\title{
Incentive or Punitive Measure? Analysis of Environmental Regulations in Construction and Demolition Waste Recycling
}

\author{
Jingsong Yang $\mathbb{D}^{1},{ }^{1}$ Jing Zhang $\mathbb{D}^{1},{ }^{1}$ Chunxiang Guo $\mathbb{D}^{2},{ }^{2}$ Ruwen Tan $\mathbb{D}^{1},{ }^{1}$ and Minjiu Yu $\mathbb{D}^{1}$ \\ ${ }^{1}$ College of Architecture and Environment, Sichuan University, Chengdu 610065, China \\ ${ }^{2}$ School of Business, Sichuan University, Chengdu 610065, China \\ Correspondence should be addressed to Minjiu Yu; yuminjiu@scu.edu.cn
}

Received 30 November 2020; Revised 25 April 2021; Accepted 24 August 2021; Published 7 September 2021

Academic Editor: Junhai Ma

Copyright ( $(2021$ Jingsong Yang et al. This is an open access article distributed under the Creative Commons Attribution License, which permits unrestricted use, distribution, and reproduction in any medium, provided the original work is properly cited.

In order to investigate the formulation of appropriate environmental regulations in construction and demolition waste (CDW) recycling, this paper establishes a CDW recycling decision-making system consisting of a contractor, a developer, and the government and analyses the decision-making results and influencing factors of the various stakeholders. Three different types of environmental regulations have been considered in the model: (i) no regulation, (ii) incentive regulation, and (iii) punitive regulation. The research shows that the incentive regulation offers the constructor greater incentives to recycle CDW and yields higher profits for members of the system, and however, when recycling is very costly and CDW is highly damaging, punitive regulation should be implemented, as the incentive regulation leads to lower social welfare. In addition, governments should be more cautious when adopting incentive regulation, because social welfare may be negative under this condition whereas there is no such possibility under the punitive regulation.

\section{Introduction}

With the rapid development of China's urbanization process, the construction of housing and municipal infrastructure has accelerated, which not only meets the needs of economic development and the public use but also generates a large amount of construction and demolition waste (CDW). It was estimated that more than 2 billion tons of CDW is generated in China annually, accounting for $30 \%-$ $40 \%$ of the total municipal solid waste [1]. In China, the vast majority of $\mathrm{CDW}$ is disposed of through simple landfill or dumping, occupying large areas of land and causing irreversible damage to the environment.

As a sustainable disposal method, recycling has drawn widespread attention from scholars, and relevant studies have shown the positive effects of CDW recycling on the environment and society [2-5]. Theoretically, CDW has high potential for recycling, and $80 \%$ of which can be reused [1]. However, as one of the largest sources of CDW in the world, the recycling rate in China is less than $10 \%$ [6]. There emerges a huge gap when compared with Germany, the
Netherlands, and other countries where the recycling rate of CDW is more than $90 \%$. How to encourage CDW recycling and reduce its environmental damage has become an urgent problem for the Chinese government.

Under the social background of ecological construction and sustainable urban development, the Chinese government began to attach greater importance to CDW recycling by issuing diverse environmental regulations in recent years. In the "Regulations for the management of urban construction waste" enacted by MOHURD, the polluter-pays principle was established for CDW disposal [7]. The "Several opinions on further strengthening the management of urban planning and construction" formulated by the State Council pointed out that efforts should be made to increase the recycling rate to more than 35\% [8]. The government at all levels have also issued provincial and municipal regulations, such as "Opinions on further strengthening the utilization of CDW" in Beijing [9] and "Measures for the supervision and management of CDW" in Shenzhen [10]. However, the effectiveness of these regulations has not been as expected, and the recycling rate of CDW remains low [11]. The reason 
is that the previous regulations were mainly determined based on experience without official standards and they were not adjusted according to different external conditions [12].

Currently, the government's ineffective regulations are considered as the major reason for the failure of current CDW recycling practice $[13,14]$. According to different implementation methods, government regulations are generally divided into two types. The first is incentive regulation, which subsidizes enterprises in the form of cost compensation. For example, major Chinese cities, such as Shenzhen and Kunming, have provided financial support for developing recycling facilities for CDW [15]. Similar cases also occur in other regions and countries, such as Japan and Singapore [16]. Another type of government regulation is punitive regulation. Guangdong province, for instance, has established a regulation "Guiding opinions on regulating the price of urban construction waste disposal management" in 2013 for a CDW disposal charging fee [17]. It can be seen that the government faces choices when formulating regulations, and proper regulations have a greater effect on promoting CDW recycling [18]. Thus, it is imperative to investigate the formulation of optimal regulations.

The recycling of CDW is a complex process involving multiple stakeholders mainly including the contractor, the developer, and the government. Their focus can be quite different: enterprises are more concerned about economic benefits while the government pays more attention to social and environmental benefits [19]. The interaction of stakeholders influences decisions on CDW recycling and consequently affects the efficiency of waste recycling, which means that interactions between these major stakeholders should not to be neglected when investigating CDW recycling [20]. Through a comprehensive literature review, we found that there are two research gaps have not been mentioned in previous studies. Firstly, the different types of regulations have not yet been distinguished in previous studies on CDW recycling. Secondly, previous studies failed to consider the interaction between different stakeholders in the CDW recycling process. The above research gaps may largely limit the implementation effect of waste recycling. Based on this, the research questions to be solved in this study are as follows:

(1) Under what conditions should the government adopt incentive or punitive environmental regulations?

(2) How do exogenous factors such as the recycling cost and environmental damage degree of CDW affect the performance of the system?

(3) Under different environmental regulations, how do the government, constructor, and developer determine their optimal decisions?

To solve these questions, we develop a CDW recycling decision-making system including a contractor, a developer, and the government. Based on the Stackelberg game, we identify and compare the decisions of the stakeholders under no regulation, incentive regulation, and punitive regulation. We also analyse the applicable conditions and optimal decisions of each environmental regulation from the perspective of the government. To the best of our knowledge, this paper makes the first attempt to compare the implementation performance of different environmental regulations in consideration of the dynamic impact of various stakeholders in the waste recycling process. It is anticipated that this study will enrich the existing body of knowledge on CDW recycling and provide a theoretical basis for the formulation and optimization of government regulations.

The rest of the paper is organized as follows. Section 2 reviews the related literature. Section 3 describes the notations and assumptions of the model. Section 4 establishes and solves the decision models under different environmental regulations. Section 5 analyses the results of the equilibrium solutions. Section 6 discusses the main research results and the final section concludes the paper.

\section{Literature Review}

2.1. CDW Recycling under Government Regulations. In recent years, researchers have investigated the effect of government regulations on CDW recycling. Ajayi and Oyedele [21] found that reasonable regulations and fiscal policies would increase the efficiency of CDW recycling, and six key measures were deemed to be significant. Huang et al. [22] pointed out that many recycling companies in China are in fiscal deficit and it is urgent for the government to provide appropriate financial incentives to promote waste recycling. Similarly, many studies proved the positive effect of government regulations on CDW recycling [23, 24].

Given the critical role of government regulations in CDW recycling, there is a large amount of studies on regulatory strategies. For example, Jia et al. [25] introduced a penalty and subsidy mechanism and developed a system dynamics model to calculate reasonable values for the subsidies and penalties. Liu et al. [26] used the same method to simulate the environmental benefits of CDW recycling and found that the government could improve the environmental benefits by adjusting the subsidies for recycling enterprises. Chen and Yuan [27] established a CDW recycling subsidy model, in which the simulation results demonstrated that increasing the subsidy amount can effectively promote waste recycling and adopting an appropriate waste landfill fee policy can enhance the implementation effect of the subsidy policy. Liu et al. [28] analysed the costs and benefits of the CDW disposal process from the perspective of contractors and society, simulated the impact of subsidies and fines, and proposed a strategy of "combination of reward and punishment" to promote the recycling of CDW.

Previous studies on CDW recycling conducted in-depth investigation on the impacts of government regulations and regulatory strategies. However, most previous studies only analysed a certain type of environmental regulation, and few studies comprehensively compared the effectiveness of different environmental regulations. In fact, the government faces choices when formulating environmental regulations, and different environmental regulations will affect the contractor's decisions on waste recycling [29]. Therefore, our study aims to endogenize the government's regulatory 
decision-making and compare the performance of the CDW recycling decision-making system under different environmental regulations in order to fill this research gap.

\subsection{Decision-Making Behavior of Stakeholders in $C D W$} Recycling. In the recycling field, scholars have conducted studies on the decision-making and behavior of stakeholders. Sheu and Gao [30] used the Nash equilibrium to investigate how bargaining power influences the negotiations between different firms. Lu et al. [31] study the cooperation of multiple firms in recycling operations. Furthermore, some scholars studied similar problems in CDW recycling. Begum et al. [32] studied the influencing factors of the contractor's attitude and behavior towards waste management and found that a positive attitude can lead to better recycling behavior. Wu et al. [33] found that the behavior of contractors was most affected by the economic feasibility and noted that contractors dump waste at will if they are not regulated by the government. Some studies have also proved that the contractor's recycling decision largely depends on the economic benefits of CDW recycling [34, 35].

Differing from contractors, Chen et al. [36] believe that the government's decision-making behavior related to CDW recycling depends more on the environmental and social benefits obtained. As a regulator, the government has realized that the core missions of current CDW management are to increase recycling rate and promote sustainable development. As proposed by Joseph [37], the government has formulated a series of policies and regulations to guide the behavior of contractors. However, due to limited resources and other reasons, these strategies have not been implemented well, and some contractors still ignore the rules to maximize economic benefits.

Different stakeholders have different concerns, which leads to conflicts and uncertainties when they make decisions on waste recycling [38]. The decisions of the government and the contractor influence each other: the government makes decisions based on the choice of the contractor, and the contractor also considers the influence of the government's regulatory choices when making decisions to maximize the economic benefits [19]. Therefore, the decision-making of these main stakeholders is a dynamic process, which means that the interactions between stakeholders must not be neglected when investigating CDW recycling.

The current studies are more related to identifying the factors affecting the stakeholders' behavior in CDW recycling. However, none of them have investigated the impact of stakeholders' interactions on the decisions and behavior of stakeholders. Therefore, we regard the government as the leader of the decision chain and adopt the Stackelberg game model to analyse the government's regulatory strategy and the dynamic interaction between different stakeholders in the CDW recycling process.

\section{Model Description and Assumptions}

3.1. Model Description. Our analysis, based on data from the China Construction Industry Association [39], shows that the top 7 companies control more than $40 \%$ of the total construction capacity. Therefore, we consider a single channel model without competition to capture a high market share of the enterprise such as China State Construciton. The CDW recycling decision-making system, consisting of a contractor, a developer, and the government, is shown in Figure 1, where the resource flow, capital flow, and waste flow represent the flow of construction products, capital, and CDW, respectively. The developer decides the construction quantity $q$ and buys construction products from the contractor at construction price $\omega$ per unit. After completion acceptance, the developer sells them to consumers at price $p$. Similar to Alizamir et al. [40], we adopt the stylized demand function given by

$$
p(q)=a-b q,
$$

where $a>0$ is the price cap of the demand function and $b>0$ is the price sensitivity parameter. There are two ways for the contractor to handle the CDW generated during the construction process: recycling or disposal, and the recycling rate $\tau$ is determined by the maximization of profit. $M$ and $N$ represent the amounts of recycling and disposal, respectively. The contractor's total unit cost of construction and disposal is $c$. Compared with disposal, the additional cost of recycling is $\gamma M^{2} / 2$, where $\gamma$ is the CDW recycling cost coefficient $[41,42]$. When the contractor recycles CDW as recycled materials, some raw materials are saved, and it is assumed that the contractor's construction cost saved from CDW recycling is expressed as $A$.

The government guides the contractor to recycle CDW by formulating appropriate environmental regulations, with the goal of maximizing social welfare. We consider two types of environmental regulations: the government can choose to offer a subsidy rate $s$ for each unit of recycled CDW under the incentive regulation or impose a rate of disposal charging fee $k$ on each unit of disposed CDW under the punitive regulation. The government can also take no measures.

There are three cases for comparison: no regulation (Case 0 ), incentive regulation (Case 1 ), and punitive regulation (Case 2). Under each case, the decision sequence of all stakeholders is the same and their decisions will influence each other. Firstly, the government chooses an appropriate environmental regulation based on the current situation. Secondly, the contractor determines the recycling rate of CDW and the construction price given by the government's environmental regulation. Finally, the developer determines the quantity of construction products. The decision sequence is shown in Figure 2.

3.2. Notations. The description of notations is shown Table 1.

\subsection{Assumptions}

(1) Considering the feasibility of solving the model, we ignore the horizontal competition problem, and only consider the situation with one contractor and one developer. 


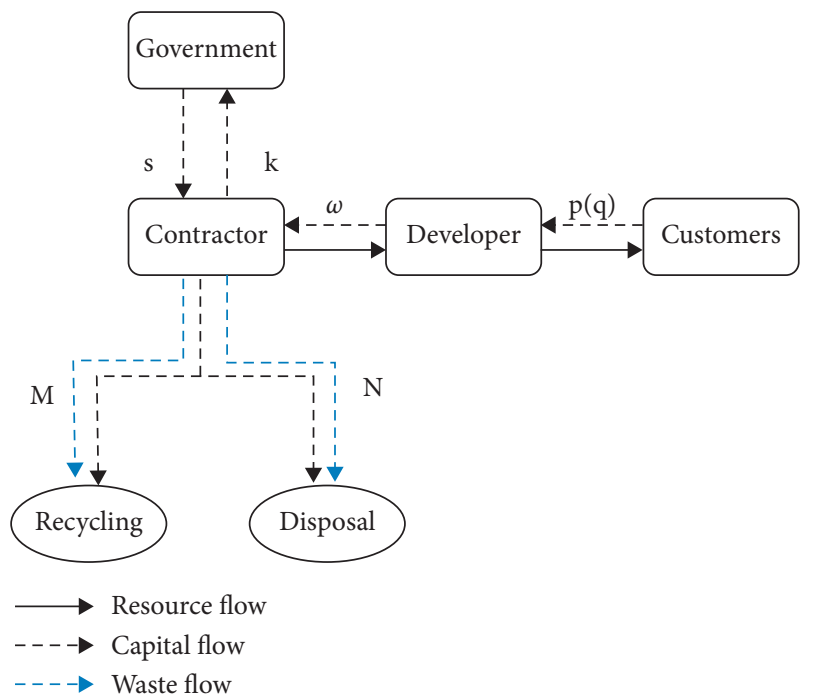

FIgURE 1: The CDW recycling decision-making system.

(2) All stakeholders are risk-neutral, and they have different concerns. The government pursues social welfare maximization, while the contractor and the developer are profits driven.

(3) The conversion coefficient between CDW generation $Q$ and the amount of construction products $q$ is $\theta$ $(0<\theta<1)$, i.e., $Q=\theta q$. Combining the waste recycling rate $\tau$, we can obtain the recycling amount $M=Q \tau$, and the disposal amount $N=Q(1-\tau)$.

(4) The environmental damage caused by waste disposal is $\delta N^{2} / 2$, where $\delta>0$ is the environmental effect coefficient. A larger $\delta$ indicates a higher degree of environmental damage from the disposal of CDW $[43,44]$.

(5) According to previous studies, the contractor's economic benefits (construction cost saving) from CDW recycling are far less than the recycling cost [27], i.e., $A<(1 / 2) \gamma M^{2}$. To simplify the model, we normalize the construction cost saving to zero. This does not affect our final results.

(6) If the government chooses an incentive regulation, the contractor will receive a subsidy based on the recycling amount, which is $s M[45,46]$; if the government chooses a punitive regulation, the contractor will pay a disposal charging fee based on the disposal amount, which is $k N$ [41].

(7) The social welfare function is as follows:

$$
\mathrm{SW}=(a-c) q-\frac{1}{2} b q^{2}-\frac{1}{2} \gamma M^{2}-\frac{1}{2} \delta N^{2}
$$

where the first two terms are the traditional social welfare derived from $\int_{0}^{q}[p(x)-c] \mathrm{d} x=(a-c) q-(1 / 2) b q^{2}[40,47]$, and the second term and third term represent the recycling cost and the environmental damage, respectively. In addition, the recycling cost and the environmental damage are added in the function to reflect the government's environmental considerations.

\section{Model Development}

4.1. Benchmark Model under No Environmental Regulation (Case 0). In this case, CDW disposal is not regulated by the government, and the contractor and the developer make corresponding decisions to maximize their own profit. Based on the above assumptions, the profit functions of the contractor and the developer are as follows:

$$
\begin{aligned}
& \max \Pi_{C}=(\omega-c) q-\frac{1}{2} \gamma M^{2}=(\omega-c) q-\frac{1}{2} \gamma \theta^{2} q^{2} \tau^{2}, \\
& \max \Pi_{D}=p-\omega q=(a-b q-\omega) q .
\end{aligned}
$$

We use the backward induction method to find the optimal solution. For $\Pi_{D}$, we have $\left(\mathrm{d}^{2} \Pi_{D} / \mathrm{d}^{2} q\right)=-2 b<0$; so, $\Pi_{D}$ is concave in $q$. Differentiating equation (3) with respect to $q$, we have

$$
\frac{\partial \Pi_{D}}{\partial q}=a-2 b q-\omega .
$$

Solving the optimal value of the developer's decision variable $q$ using the first order optimality condition that $\left(\partial \Pi_{D} / \partial q\right)=0$, we then obtain

$$
q(\omega)=\frac{a-\omega}{2 b} .
$$

With substituting this $q$ into equation (3), we obtain the contractor's profit $\Pi_{C}$. Next, the contractor optimizes its decisions on the construction price $\omega$ and the recycling rate $\tau$ by solving the first-order optimality conditions. In order to guarantee a maximum, Hessian matrix of $\Pi_{C}$ should be negative definite:

$$
H_{\Pi_{C}}=\left[\begin{array}{cc}
\frac{\partial^{2} \Pi_{C}}{\partial^{2} \omega} & \frac{\partial^{2} \Pi_{C}}{\partial \omega \partial \tau} \\
\frac{\partial^{2} \Pi_{C}}{\partial \tau \partial \omega} & \frac{\partial^{2} \Pi_{C}}{\partial^{2} \tau}
\end{array}\right]=\left[\begin{array}{cc}
-\frac{4 b+\gamma \theta^{2} \tau^{2}}{4 b^{2}} & \frac{\gamma \theta^{2} \tau(a-\omega)}{2 b^{2}} \\
-\frac{\gamma \theta^{2}(a-\omega)^{2}}{4 b^{2}} & -\frac{\gamma \theta^{2}(a-\omega)^{2}}{4 b^{2}}
\end{array}\right] .
$$

Since $H_{1 \times 1}=-\left(4 b+\gamma \theta^{2} \tau^{2} / 4 b^{2}\right)<0, H_{2 \times 2}=\left(\gamma \theta^{2}(4 b+\right.$ $\left.\left.\gamma \theta^{2} \tau(2 a+\tau-2 \omega)\right)(a-\omega)^{2} / 16 b^{4}\right)>0, \Pi_{C}$ is concave in $\omega$ and $\tau$. Let $\left(\partial \Pi_{C} / \partial \omega\right)=\left(\partial \Pi_{C} / \partial \tau\right)=0$ :

$$
\begin{aligned}
& \frac{\partial \Pi_{C}}{\partial \omega}=q+\frac{(\omega-c)}{-2 b}+\frac{\gamma q \theta^{2} \tau^{2}}{2 b}=0, \\
& \frac{\partial \Pi_{C}}{\partial \tau}=-\gamma \tau q^{2} \theta^{2}=0 .
\end{aligned}
$$

Solving equations (8) and (9) simultaneously, we get

$$
\begin{aligned}
\omega(\tau) & =\frac{2 a b+2 b c+a \gamma \theta^{2} \tau^{2}}{4 b+\gamma \theta^{2} \tau^{2}}, \\
\tau & =0 .
\end{aligned}
$$

This means that the contractor has no incentive to recycle CDW if no environmental regulation is formulated. Substituting equation (11) back into equations (3)-(10), we 


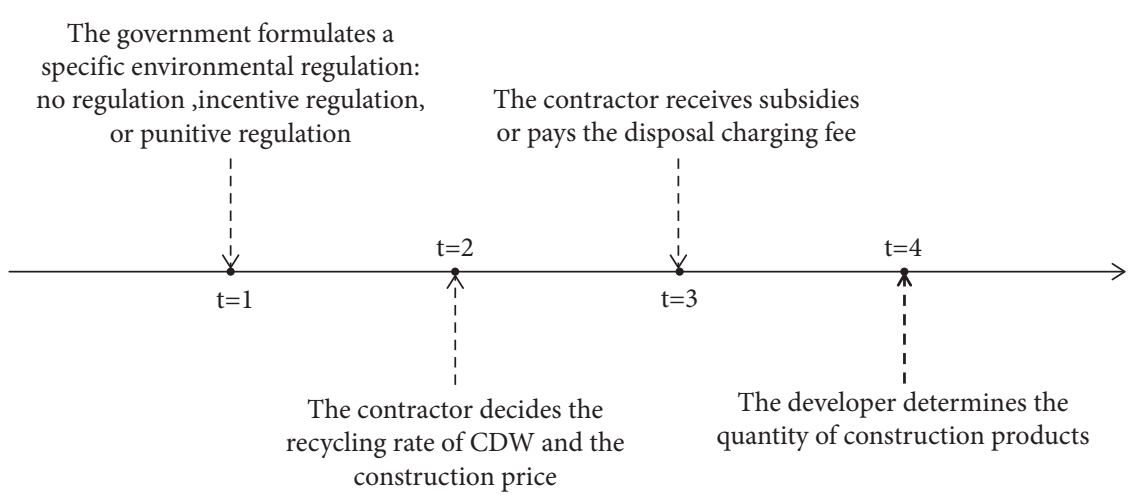

Figure 2: Decision sequence in the CDW recycling system.

TABle 1: Notations used in the model.

\begin{tabular}{|c|c|}
\hline Notations & Description \\
\hline & Parameters \\
\hline$a$ & The price cap of the demand function, $0<a$ \\
\hline$b$ & The price sensitivity to demand quantity, $0<b$ \\
\hline$c$ & Contractor's total unit cost of construction and disposal, $0<c<a$ \\
\hline$\gamma$ & Contractor's CDW recycling cost coefficient, $0<\gamma$ \\
\hline$\delta$ & Environmental effect coefficient of $\mathrm{CDW}, 0<\delta$ \\
\hline$\theta$ & Conversion coefficient between the amount of CDW and construction products, $0<\theta \leq 1$ \\
\hline A & Contractor's construction cost saved from CDW recycling, $0 \leq A<(1 / 2) \gamma M^{2}$ \\
\hline & Decision variables \\
\hline$s$ & Subsidy rate, $0<s$ \\
\hline$k$ & The rate of disposal charging fee, $0<k$ \\
\hline$\tau$ & Contractor's recycling rate of CDW, $0 \leq \tau<1$ \\
\hline$\omega$ & The construction price of the construction products that the contractor provides to the developer, $0<\omega<p(q)$ \\
\hline$q$ & The quantity of construction products determined by the developer, $0<q$ \\
\hline$p(q)$ & The sales price of the construction products that the developer provides to consumers, $p(q)=a-b q>0$ \\
\hline Q & Total amount of CDW generated, $Q=\theta q$ \\
\hline & Derived functions \\
\hline$M$ & The recycling amount of CDW, $M=Q \tau$ \\
\hline$N$ & The disposal amount of CDW, $N=Q(1-\tau)$ \\
\hline$\Pi_{C}$ & Profit of the contractor \\
\hline$\Pi_{D}$ & Profit of the developer \\
\hline SW & Social welfare \\
\hline & Superscripts (the superscripts correspond to optimal solutions in each case) \\
\hline$R$ & Incentive regulation \\
\hline$P$ & Punitive regulation \\
\hline 0 & No regulation \\
\hline
\end{tabular}

obtain other equilibrium solutions under no environmental regulation as follows:

$$
\begin{aligned}
\omega^{0} & =\frac{(a+c)}{2}, \\
q^{0} & =\frac{a-c}{4 b}, \\
\Pi_{C}^{0} & =\frac{(a-c)^{2}}{8 b}, \\
\Pi_{D}^{0} & =\frac{(a-c)^{2}}{16 b} . \\
\mathrm{SW}^{0} & =\frac{(a-c)^{2}\left(7 b-\delta \theta^{2}\right)}{32 b^{2}} .
\end{aligned}
$$

4.2. The Model under Incentive Regulation (Case 1). In this case, the government subsidizes the contractor to promote the recycling of CDW. According to the previous assumptions, the contractor's decision-making objective becomes

$$
\max \Pi_{C}=(\omega-c) q-\frac{1}{2} \gamma M^{2}+s M
$$

The developer's objective is

$$
\max \Pi_{D}=(a-b q-\omega) q .
$$

The government seeks to maximize social welfare, and its objective is

$$
\max \mathrm{SW}=(a-c) q-\frac{1}{2} b q^{2}-\frac{1}{2} \gamma M^{2}-\frac{1}{2} \delta N^{2} .
$$


Similarly, we use the backward induction method to obtain their respective equilibrium solutions:

$$
\begin{aligned}
s & =\frac{(a-c) \gamma \delta \theta}{4 b(\gamma+\delta)}, \\
\tau^{R} & =\frac{\delta}{\gamma+\delta}, \\
\omega^{R} & =\frac{(a+c)}{2}, \\
q^{R} & =\frac{a-c}{4 b}, \\
\Pi_{C}^{R} & =\frac{(a-c)^{2}\left(4 b(\gamma+\delta)^{2}+\gamma \delta^{2} \theta^{2}\right)}{32 b^{2}(\gamma+\delta)^{2}}, \\
\Pi_{D}^{R} & =\frac{(a-c)^{2}}{16 b}, \\
\mathrm{SW}^{R} & =\frac{(a-c)^{2}\left(7 b \gamma+7 b \delta-\gamma \delta \theta^{2}\right)}{32 b^{2}(\gamma+\delta)} .
\end{aligned}
$$

4.3. The Model under Punitive Regulation (Case 2). In this case, the government imposes a disposal charging fee on the contractor to control the contractor's waste disposal behavior. The contractor's decision-making objective becomes

$$
\max \Pi_{C}=(\omega-c) q-\frac{1}{2} \gamma M^{2}-k N .
$$

The developer's objective is

$$
\max \Pi_{D}=(a-b q-\omega) q .
$$

The government still seeks to

$$
\max \mathrm{SW}=(a-c) q-\frac{1}{2} b q^{2}-\frac{1}{2} \gamma M^{2}-\frac{1}{2} \delta N^{2} .
$$

According to the backward induction method, the solution process of $q(\omega)=(a-\omega / 2 b)$ is the same as equation (5). The contractor optimizes its decisions on the construction price $\omega$ and the recycling rate $\tau$ by simultaneously solving the first-order optimality conditions: $\left(\partial \Pi_{C} / \partial \omega\right)=0$, $\left(\partial \Pi_{C} / \partial \tau\right)=0$. This yields the following solution:

$$
\begin{aligned}
\omega & =\frac{2 a b+2 c b+2 k b \theta-2 \tau k b \theta+a \gamma \theta^{2} \tau^{2}}{4 b+\gamma \tau^{2}}, \\
\tau & =\frac{4 k b}{(a-c-k) \gamma} .
\end{aligned}
$$

Combining equations (20) and (21), we further have

$$
\omega=\frac{a+c+\theta k}{2} .
$$

Interestingly, the construction price in the benchmark model and the incentive model is equal, i.e., $\omega^{0}=\omega^{R}=(a+c / 2)$, while the construction price in the punitive model $\omega^{P}=((a+c+\theta k) / 2)$. This suggests that the contractor essentially transfers part of the disposal charging fee to the developer under the punitive regulation, which is in contrast to the case of no pass-through of the subsidy received under the incentive regulation. Considering the above responses, the government sets the rate of disposal charging fee to maximize social welfare, and by solving $(\partial S W / \partial k)=0$, we obtain the optimal rate of disposal charging fee as

$$
k= \begin{cases}\frac{(a-c) \gamma \theta\left(4 b \delta-3 b \gamma+\gamma \delta \theta^{2}\right)}{16 b^{2} \gamma+16 b^{2} \delta+b \gamma^{2} \theta^{2}+8 b \gamma \delta \theta^{2}+\gamma^{2} \delta \theta^{4}}, & \delta>\delta_{0}, \\ 0, & \delta \leq \delta_{0},\end{cases}
$$

where $\delta_{0}=\left(3 b \gamma /\left(4 b+\gamma \theta^{2}\right)\right)$, which means that when $\delta \leq \delta_{0}$, no disposal fee will be imposed and the punitive regulation will degenerate to the no environmental regulation case. To focus on the effect of environmental regulation, then we consider the punitive regulation with a positive disposal fee, i.e., $\delta>\delta_{0}$. Based on the optimal rate of disposal charging fee, we get the equilibrium solutions under the punitive regulation as follows:

$$
\begin{aligned}
k & =\frac{(a-c) \gamma \theta\left(4 b \delta-3 b \gamma+\gamma \delta \theta^{2}\right)}{16 b^{2} \gamma+16 b^{2} \delta+b \gamma^{2} \theta^{2}+8 b \gamma \delta \theta^{2}+\gamma^{2} \delta \theta^{4}} \\
\tau^{P} & =\frac{4 b \delta-3 b \gamma+\delta \gamma \theta^{2}}{(\gamma+\delta)\left(4 b+\gamma \theta^{2}\right)} \\
\omega^{P} & =\frac{2 b c(\gamma+\delta)\left(4 b+\gamma \theta^{2}\right)+a\left(8 b^{2}(\gamma+\delta)-b \gamma(\gamma-6 \delta) \theta^{2}+\gamma^{2} \delta \theta^{4}\right)}{16 b^{2}(\gamma+\delta)+b \gamma(\gamma+8 \delta) \theta^{2}+\gamma^{2} \delta \theta^{4}} \\
q^{P} & =\frac{(a-c)(\gamma+\delta)\left(4 b+\gamma \theta^{2}\right)}{b \gamma\left(16 b+\gamma \theta^{2}\right)+\delta\left(4 b+\gamma \theta^{2}\right)^{2}}
\end{aligned}
$$




$$
\begin{aligned}
\Pi_{C}^{P} & =\frac{(a-c)^{2}\left(\beta \gamma^{2}\left(64 b^{2}+41 b \gamma \theta^{2}+4 \gamma^{2} \theta^{4}\right)+2 \delta b \gamma\left(64 b^{2}+20 b \gamma \theta^{2}+\gamma^{2} \theta^{4}\right)+\delta^{2}\left(4 b+\theta^{2} \gamma\right)^{3}\right)}{2\left(\delta\left(4 b+\gamma \theta^{2}\right)^{2}+b \gamma\left(16 b+\gamma \theta^{2}\right)\right)^{2}}, \\
\Pi_{D}^{P} & =\frac{b(a-c)^{2}(\delta+\gamma)^{2}\left(4 b+\gamma \theta^{2}\right)^{2}}{\left(\delta\left(4 b+\gamma \theta^{2}\right)^{2}+b \gamma\left(16 b+\gamma \theta^{2}\right)\right)^{2}}, \\
\operatorname{SW}^{P} & =\frac{(a-c)^{2}(\delta+\gamma)\left(7 b+\gamma \theta^{2}\right)}{2\left(b \gamma\left(16 b+\gamma \theta^{2}\right)+\delta\left(4 b+\gamma \theta^{2}\right)^{2}\right)} .
\end{aligned}
$$

Based on the results above, all the optimal solutions and derived functions are summarized in Table 2.

\section{Model Analysis}

This section first discusses the impacts of environmental damage and recycling cost on the decisions and performances of the CDW recycling decision-making system. Then, a comprehensive comparison of the equilibrium solutions in three cases is conducted. The proofs of all propositions below are given in Appendix.

5.1. The Impact of Environmental Damage and Recycling Cost under Incentive Regulation

Proposition 1. In Case 1:

(1) $(\partial s / \partial \delta)>0,(\partial s / \partial \gamma)>0$.

(2) $\left(\partial Q^{R} / \partial \delta\right)=0,\left(\partial Q^{R} / \partial \gamma\right)=0$.

(3) $\left(\partial M^{R} / \partial \delta\right)>0,\left(\partial M^{R} / \partial \gamma\right)<0$.

Proposition 1 shows that when the degree of environmental damage increases, the government's optimal subsidy increases to encourage $C D W$ recycling. Therefore, the amount of recycling increases as well. When the cost of recycling increases, the government's optimal subsidy increases and the amount of recycling decreases. Proposition 1 (2) also suggests that since the contractor does not transfer the subsidy to the developer, neither the degree of environmental damage nor recycling cost has an impact on total amount of CDW.

Proposition 2. In Case 1:

(1) $\left(\partial \Pi_{C}^{R} / \partial \delta\right)>0$.

(2) if $\delta>\gamma,\left(\partial \Pi_{C}^{R} / \partial \gamma\right)>0$; otherwise, $\left(\partial \Pi_{C}^{R} / \partial \gamma\right) \leq 0$.

(3) $\left(\partial \Pi_{D}^{R} / \partial \delta\right)=0,\left(\partial \Pi_{D}^{R} / \partial \gamma\right)=0$.

Proposition 2 suggests that when the degree of environmental damage increases, the contractor's profit increases; when the recycling cost increases, the change of the contractor's profit depends on how environmentally damaging the CDW is. Specifically, if the degree of damage is sufficiently high, the recycling cost is positively correlated with the contractor's profit; otherwise, the recycling cost is negatively correlated with the contractor's profit. Under the incentive regulation, the contractor's profit increases with the degree of damage. This is because two effects arise when the degree of damage is higher. First, the government offers a higher subsidy, which benefits the contractor. Second, the higher subsidy also induces more CDW recycling, which makes the contractor incur higher costs. The first effect is positive for the contractor, but the second is negative. Our results indicate that the degree of the positive effect always dominates that of the negative one, and thus, the contractor benefits when damage is higher under the incentive regulation. In addition, since the contractor does not transfer the subsidy to the developer, the developer's profit is independent of the two exogenous variables, as shown by Proposition 2 (3).

5.2. The Impact of Environmental Damage and Recycling Cost under Punitive Regulation

Proposition 3. In Case 2:

(1) $(\partial k / \partial \delta)>0$; if $\delta_{0}<\delta<\delta_{1},(\partial k / \partial \gamma)<0, \quad$ otherwise, $(\partial k / \quad \partial \gamma) \geq 0$, where $\delta_{1}=\left(24 b^{2} \gamma+3 b \gamma^{2} \theta^{2}+\sqrt{3}\right.$ $\sqrt{448 b^{4} \gamma^{2}+} 176 b^{3} \gamma^{3} \theta^{2}+19 b^{2} \gamma^{4} \theta^{4} / 2\left(16 b^{2}+8 b \gamma \theta^{2}+\right.$ $\left.\gamma^{2} \theta^{4}\right)$ ).

(2) $\left(\partial Q^{P} / \partial \delta\right)<0$; if $\quad \delta_{0}<\delta<\delta_{1},\left(\partial Q^{P} / \quad \partial \gamma\right)>0$, otherwise, $\left(\partial Q^{P} / \partial \gamma\right) \leq 0$.

(3) $\left(\partial M^{P} / \partial \delta\right)>0,\left(\partial M^{P} / \partial \gamma\right)<0$.

Proposition 3 (1) suggests that the optimal disposal charging fee increases when the $C D W$ is more damaging to the environment, and it is nonmonotonic with respect to the recycling cost, depending on the current degree of damage. The reasons are as follows: (i) when the degree of environmental damage is within an acceptable range, the government places more emphasis on economic efficiency and decreases the disposal charging fee to encourage the contractor to create higher profit; (ii) when the degree of environmental damage is sufficiently high, the government is more concerned about environmental protection and suppresses the contractor's disposal behavior by increasing the disposal charging fee. These indicate that the government should fully consider the relationship between economic development and environmental protection when adopting a punitive regulation. Proposition 3 (2) shows that the total amount of $C D W$ 


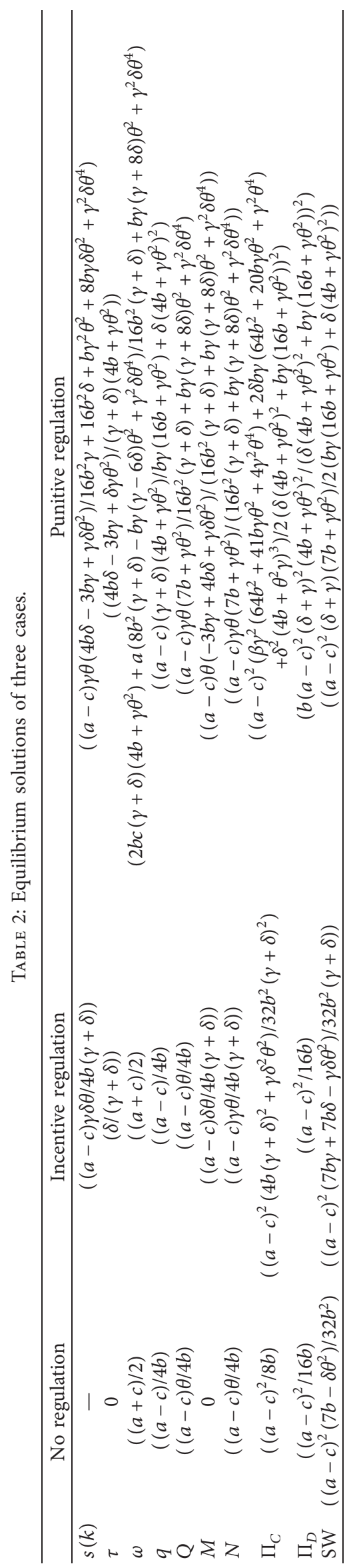


decreases as the degree of environmental damage increases; the impact of the recycling cost on the total amount of CDW also depends on the degree of environmental damage, and the impacts of these parameters on the CDW amount are opposite to their impacts to the disposal charging fee. Proposition 3 (3) shows that the recycling amount is positively related to the degree of environmental damage and negatively related to the recycling cost.

Proposition 4. In Case 2:

(1) $\left(\partial \Pi_{C}^{P} / \partial \delta\right)<0$.

(2) if $\delta_{0}<\delta<\delta_{2},\left(\partial \Pi_{C}^{P} / \partial \gamma\right)>0$, otherwise, $\left(\partial \Pi_{C}^{P} / \partial \gamma\right) \leq 0$, where $\delta_{2}$ is given in Appendix.

(3) $\left(\partial \Pi_{D}^{P} / \partial \delta\right)<0$.

(4) if $\delta_{0}<\delta<\delta_{1}$, $\left(\partial \Pi_{D}^{P} / \partial \gamma\right)>0$; otherwise, $\left(\partial \Pi_{D}^{P} / \partial \gamma\right) \leq 0$, where $\delta_{1}$ is given by Proposition 3.

Proposition 4 shows that the contractor's and the developer's profits decrease as the degree of environmental damage increases, and it is nonmonotonic in recycling cost, depending on the current degree of damage. Specifically, if the degree of environmental damage is sufficiently low, the contractor will accrue more profit when its recycling cost increases; otherwise, the contractor's profit will decrease. There are similar results concerning the developer's profit. Combining Proposition 2 enables us to reveal several useful managerial insights. First, the reduction of recycling costs is not always beneficial to enterprises. Therefore, enterprises should consider external conditions such as the degree of environmental damage and government regulations when deciding whether to invest in reducing recycling costs. Second, the contractor benefits from the incentive regulation but gets hurt under a punitive regulation when the degree of damage is higher. This further implies that the contractor might have an incentive to deliberately exaggerate the degree of damage if the incentive regulation is chosen by the government but understate the degree of damage under the punitive regulation. This suggests that it is necessary to have a third-party auditor to ensure that the environmental damage is accurately measured. For example, the Institute of Public and Environmental Affairs (IPE) is working on this (http://www.ipe.org.cn). The IPE has been cooperating with government agencies and public welfare organizations. It collects, collates, and analyzes the environmental information disclosed by the government and enterprises, and it builds an information database, so as to promote the improvement of environmental information disclosure and environmental governance mechanism.

\subsection{Comparison of Different Environmental Regulations}

Proposition 5. The following relationships of the construction price and the sales price always hold:

(1) $\omega^{0}=\omega^{R}<\omega^{P}$.

(2) $q^{0}=q^{R}>q^{P}$.

From Proposition 5, we find that the construction price in Case 2 is higher than that in both Case 0 and Case 1. In the absence of the pass-through effect, the price and quantity decisions under the incentive regulation are identical to the benchmark case. In contrast, through the pass-through effect, the construction price under the punitive regulation is higher than the price under the incentive regulation, which further affects the developer's decision of the construction quantity.

Proposition 6. The following relationships of the recycling amount and the disposal amount always hold:

(1) $0=M^{0}<M^{P}<M^{R}$.

(2) if $\gamma>2 b$ and $\delta>\delta_{3}, N^{P}<N^{R}<N^{0}$; otherwise, $N^{R} \leq$ $N^{P}<N^{0}$ where $\delta_{3}=\left(3 \gamma\left(4 b^{2}+b \gamma \theta^{2}\right) / 4 b \gamma \theta^{2}+\gamma^{2} \theta^{4}-12 b^{2}\right)$.

Proposition 6 (1) shows that both environmental regulations can encourage the contractor to carry out CDW recycling, but the contractor is more motivated under the incentive regulation. The explanations are as follows. First, the contractor receives all the subsidies under the incentive regulation, which means all the subsidies directly contribute to $C D W$ recycling. In contrast, the contractor transfers part of the disposal charging fee to the developer under the punitive regulation, resulting in the disposal charging fee being unable to play its full role. Second, the government needs to balance economic development and environmental protection under the punitive regulation, while it is not necessary under the incentive regulation. Therefore, the government should be aware that the incentive regulation always provides a higher incentive for $C D W$ recycling than the punitive regulation.

Proposition 6 (2) shows that the disposal amount is the highest in Case 0, and the relationship of the disposal amount between Case 1 and Case 2 depends on the two exogenous variables: the environmental effect coefficient and the recycling cost coefficient. Specifically, the disposal amount under the punitive regulation is greater when exogenous variables are small. Based on the above results, the following regulatory strategy can be determined: the government should give priority to punitive regulation if the degree of environmental damage is sufficiently high and the recycling of CDW is very costly; otherwise, incentive regulation is a better choice.

For better understanding, numerical simulations were carried out, as shown in Figures 3 and 4, where $a=20, b=1, c=10, \delta=2, \gamma=2, \theta=1$.

Proposition 7. The following profit relationships always hold:

(1) $\Pi_{C}^{P}<\Pi_{C}^{0}<\Pi_{C}^{R}$.

(2) $\Pi_{D}^{P}<\Pi_{D}^{0}=\Pi_{D}^{R}$.

Proposition 7 compares the profits of the contractor and the developer under different regulations. For the contractor, the profit is at its lowest level in Case 2 and at its highest level in Case 1. For the developer, since there is no pass-through effect in Case 1, the government's choice of the incentive regulation does not affect its profit. In contrast, the contractor transfers part of the disposal charging fee to the developer through a pass-through effect for its own benefit in Case 2. This behavior reduces the developer's profit, resulting in the 


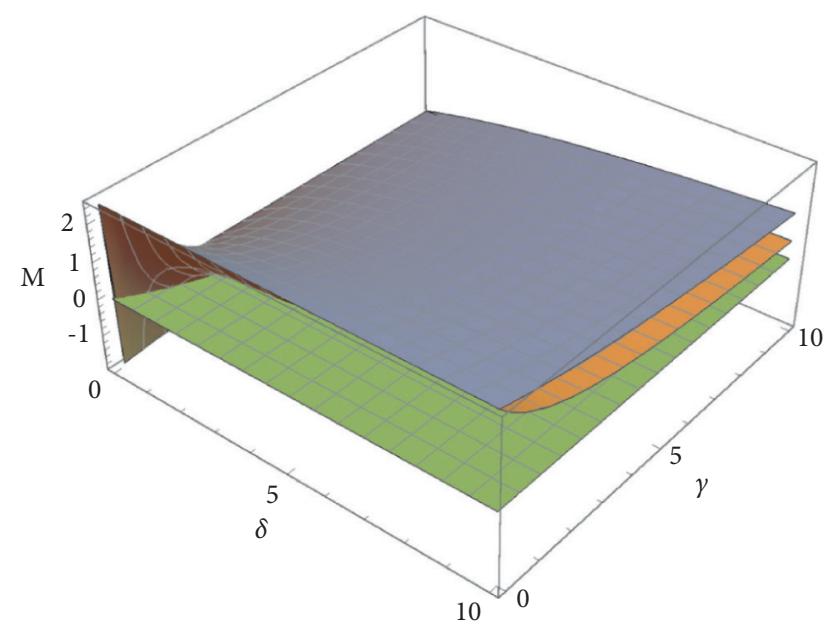

No regulation

Incentive regulation

Punitive regulation

Figure 3: The recycling amount under different regulations.

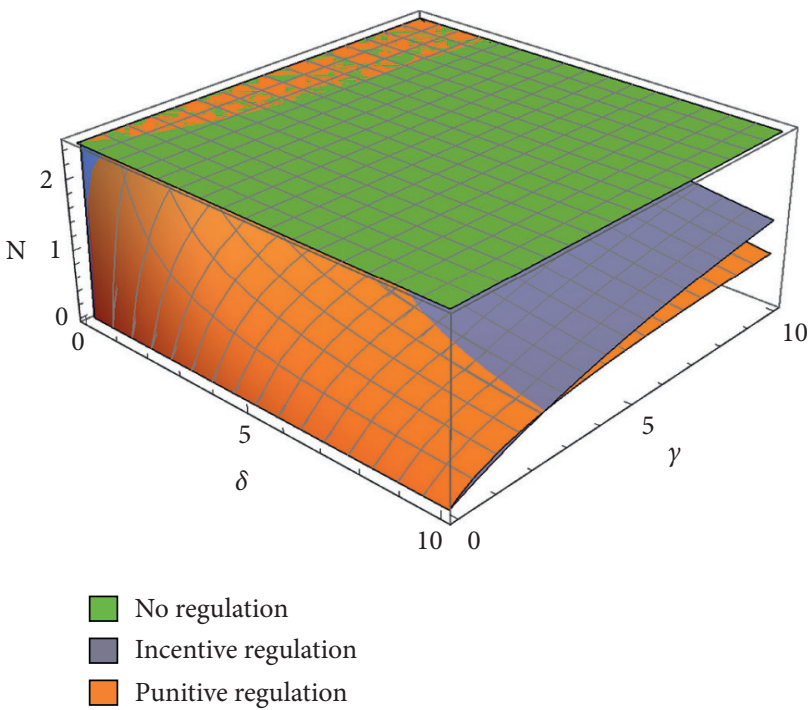

Figure 4: The disposal amount under different regulations.

developer's profit being the lowest under the punitive regulation among all three cases.

To facilitate a better understanding, we summarize the results of Proposition 7 in Figures 5 and 6, where $a=20, b=1, c=10, \delta=2, \gamma=2, \theta=1$.

Proposition 8. The following social welfare relationships always hold:

(1) if $\gamma>\left((\sqrt{97}-1) b / 2 \theta^{2}\right)$ and $\delta>\delta_{4}, \quad S W^{0}<S W^{R}<$ $S W^{P}$; otherwise, $S W^{0}<S W^{P} \leq S W^{R}, \quad$ where $\delta_{4}=$ $\left(3 b \gamma \quad\left(5 b+2 \gamma \theta^{2}+\sqrt{b(121 b+} 16 \gamma \theta^{2}\right)\right) /\left(48 b^{2}-\right.$ $\left.\left.2 b \gamma \theta^{2}-2 \gamma^{2} \theta^{4}\right)\right)$.

(2) if $\delta<7 b, S W^{0}>0$; otherwise, $S W^{0} \leq 0$; if $\delta<\quad(7 b \gamma /$ $(\gamma-7 b)), S W^{R}>0$, otherwise, $S W^{R} \leq 0 ; S W^{P}>0$.

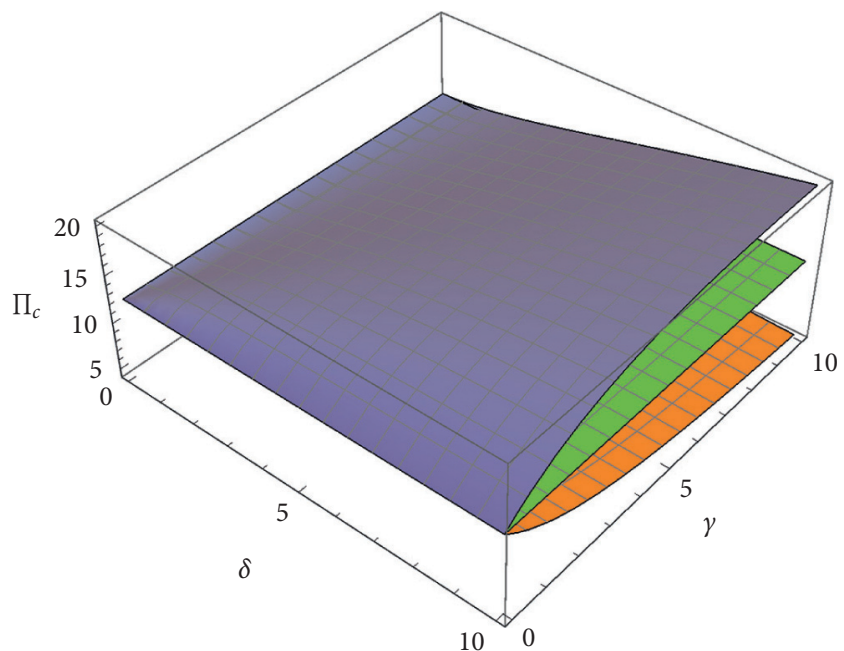

No regulation

Incentive regulation

Punitive regulation

FIgURE 5: The contractor's profit under different regulations.

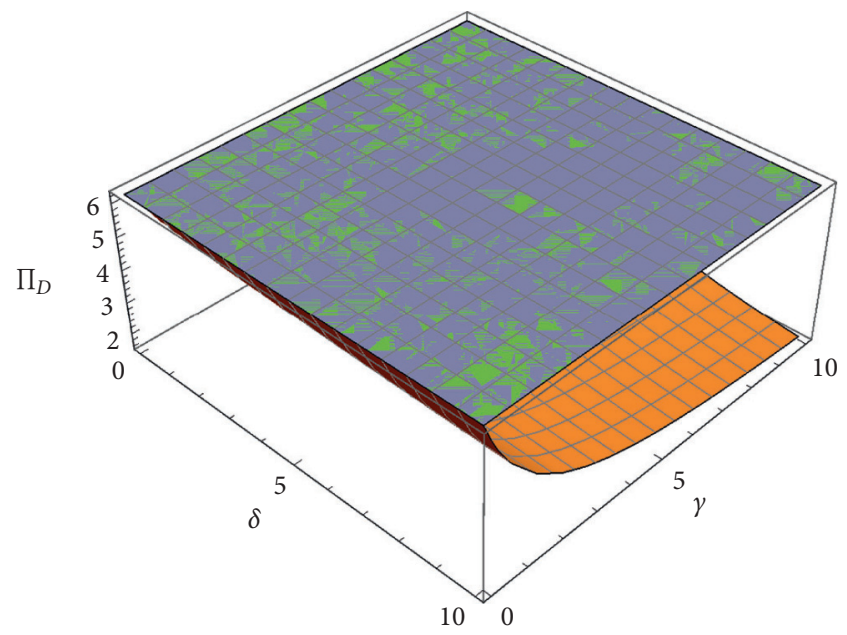

No regulation

Incentive regulation

Punitive regulation

Figure 6: The developer's profit under different regulations.

Proposition 8 (1) shows that the social welfare is at its lowest level in Case 0, which means that either environmental regulation can enhance social welfare compared to the no regulation case. Furthermore, the relationship of the social welfare between Case 1 and Case 2 depends on the environmental effect coefficient and recycling cost coefficient. Compared to the incentive regulation, the punitive regulation yields a higher social welfare only when CDW recycling is costly and the degree of damage is high. Therefore, we get a similar enlightenment as Proposition 6: the government should fully consider the degree of damage and recycling cost 
when formulating environmental regulation. When these two exogenous variables are low, the government should give priority to incentive regulation; otherwise, the punitive regulation should be adopted.

Proposition 8 (2) shows that social welfare may be negative under both no regulation and the incentive regulation when the environmental effect coefficient reaches a certain level. In contrast, social welfare is always positive under the punitive regulation. Since $\gamma$ and $b$ are both positive, we can obtain $(7 b \gamma /(\gamma-7 b))>7 b$, which indicates that social welfare is less likely to be negative under incentive regulation than that under no regulation.

For better understanding, we summarize results of Proposition 8 in Figure 7, where $a=20, b=1, c=10$, $\delta=2, \gamma=2, \theta=1$.

\section{Discussion}

In this study, we investigated the implementation effects of different types of environmental regulations in the CDW recycling system, analysed the decision-making behavior and influencing factors of the main stakeholders (i.e., the contractor, the developer, and the government) in the CDW recycling process, and obtained several new findings with management significance.

For the government, the main focus is to formulate appropriate environmental regulations to maximize social welfare. Compared with the punitive regulation, the recycling amount under the incentive regulation is larger, which suggests that the incentive regulation can better promote $\mathrm{CDW}$ recycling. However, the government should not choose the incentive regulation all the time. When the CDW recycling is costly and the degree of damage is high, the social welfare under the punitive regulation is greater. Therefore, the punitive regulation should be adopted at this time. This finding is partially consistent with the study of Yuan and Wang [12], which revealed that the waste disposal charging fee can stimulate CDW recycling behavior.

For enterprises, we find that both the contractor and the developer prefer the incentive regulation because they benefit more at this time. Interestingly, the contractor monopolizes all the subsidies under the incentive regulation and transfers part of the disposal charging fee to the developer under the punitive regulation. This pass-through effect inhibits the developer's decision of the construction quantity, thereby reducing the amount of CDW under the punitive regulation.

Previous studies have identified the main factors affecting CDW recycling within the framework of the circular economy $[48,49]$. Based on this, we analysed the impact of exogenous variables such as the degree of environmental damage and the recycling cost on the decision-making of stakeholders in CDW recycling. Under the incentive regulation, as the recycling cost increases, the change of the contractor's profit depends on the degree of environmental damage. Specifically, if the degree of damage is sufficiently high, the recycling cost is positively correlated with the contractor's profit; otherwise, the recycling cost is negatively correlated with the contractor's profit. There are similar

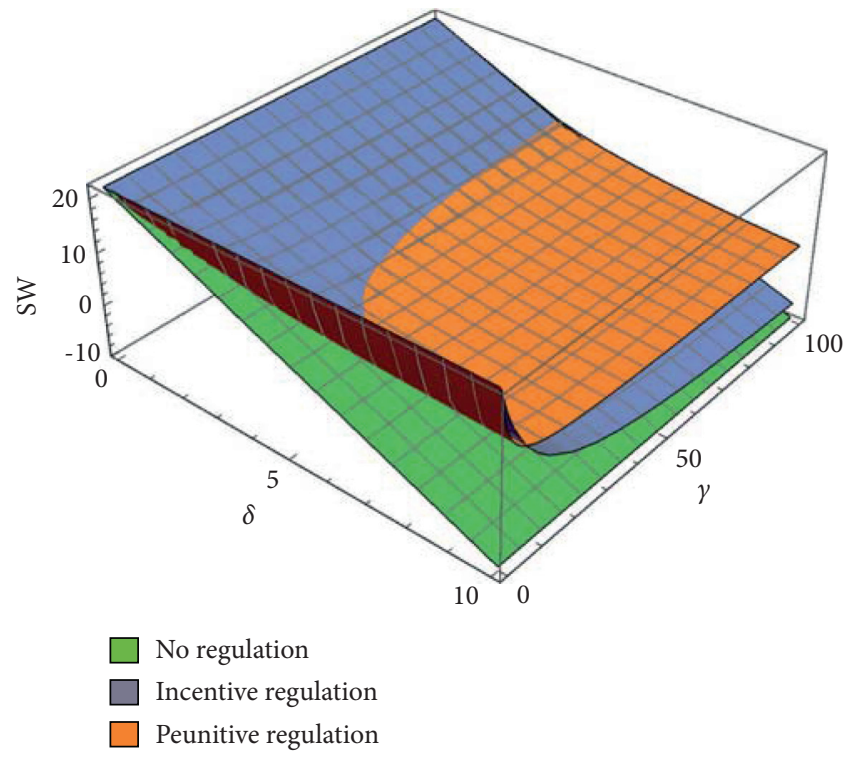

FIgURE 7: The social welfare under different regulations.

results under the punitive regulation. Consistent with the study of He and Yuan [50], we find that the decision-making of each stakeholder needs to be dynamically adjusted according to the external situation.

Obviously, different stakeholders have different concerns in regard to CDW recycling $[38,51,52]$. In line with previous studies, conflicts among the contractor, the developer, and the government in CDW recycling process were investigated. Furthermore, we complement previous studies by comparing different types of environmental regulations. The results not only provide a reference for the government to formulate relevant regulations but also help to better understand CDW recycling from the perspective of different stakeholders.

\section{Conclusions}

Recycling has been generally regarded as an effective way to reduce environmental damage from $\mathrm{CDW}$ and achieve sustainable development. Obviously, the government plays an important role in promoting CDW recycling, and the implementation of recycling is closely related to appropriate environmental regulations. Therefore, in this study, we investigated the formulation of the optimal environmental regulation of CDW recycling from the perspective of the government. Considering the differences in the decisionmaking goals of the government and enterprises, we established a CDW recycling decision-making model under three conditions, no regulation, incentive regulation, and punitive regulation, and examined the impacts of different environmental regulations.

In terms of profit, the contractor and the developer benefit more from the incentive regulation, which suggests that both prefer the incentive regulation. In addition, in order to maximize their own profit, the contractor monopolizes all subsidies under the incentive regulation and transfers part of the disposal charging fee to the developer under the punitive regulation. 
In terms of CDW recycling, the recycling amount under the incentive regulation is always greater than that under the punitive regulation, which suggests that the incentive regulation can better promote the contractor's recycling behavior. However, the incentive regulation does not always result in a lower disposal amount than the punitive regulation because the punitive regulation's pass-through effect curbs the total amount of CDW, while the incentive regulation does not. Specifically, the disposal amount under the incentive regulation exceeds that under the punitive regulation when CDW is sufficiently damaging to the environment and the recycling is very costly.

The results also show that it is necessary for the government to fully consider two important factors, the degree of environmental damage and the recycling cost, when formulating regulations. When both of them are sufficiently high, the punitive regulation should be adopted; otherwise, the incentive regulation is a better choice. Besides, the government should be more cautious when formulating the incentive regulation, because social welfare may be negative at this time and there is no such possibility under the punitive regulation.

There are also certain limitations. Firstly, our model considers only one contractor and one developer, but there are numerous companies in reality, so one key research direction is to consider a recycling system that consist of multiple contractors and multiple developers. Secondly, we assume that the government can only adopt one kind of regulation, but in the real world the government can set up multiple compound regulations at the same time, so further research should take this situation into consideration. Thirdly, considering practical factors such as information asymmetry and corporate social responsibility in a similar context may yield valuable insights.

\section{Appendix}

\section{Proof of Proposition 1}

(1) $(\partial s / \partial \delta)=\left((a-c) \gamma^{2} \theta / 4 b(\gamma+\delta)^{2}\right)>0, \quad(\partial s / \partial \gamma)=((a$ $\left.-c) \delta^{2} \theta / 4 b(\gamma+\delta)^{2}\right)>0$.

(2) $\left(\partial Q^{R} / \partial \delta\right)=0,\left(\partial Q^{R} / \partial \gamma\right)=0$.

(3) $\left(\partial M^{R} / \partial \delta\right)=\left((a-c) \gamma \theta / 4 b(\gamma+\delta)^{2}\right)>0,\left(\partial M^{R} / \partial \gamma\right)$ $=-\left((a-c) \delta \theta / 4 b(\gamma+\delta)^{2}\right)<0$.

\section{Proof of Proposition 2}

(1) $\left(\partial \Pi_{C}^{R} / \partial \delta\right)=\left(\delta(a-c)^{2} \gamma^{2} \theta^{2} / 16 b^{2}(\delta+\gamma)^{3}\right)>0$.

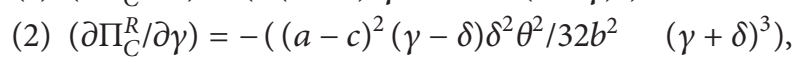
therefore, when $\delta>\gamma$, then $\left(\partial \Pi_{C}^{R} / \partial \gamma\right)>0$; when $\delta \leq \gamma$, then $\left(\partial \Pi_{C}^{R} / \partial \gamma\right) \leq 0$.

Proof of Proposition 3

(1) $(\partial k / \partial \delta)=\left(4 b(a-c) \gamma^{2} \theta\left(28 b^{2}+11 b \gamma \theta^{2}+\quad \gamma^{2} \theta^{4}\right) /\right.$ $\left.\left(16 b^{2}(\gamma+\delta)+b \gamma(\gamma+8 \delta) \theta^{2}+\gamma^{2} \delta \theta^{4}\right)^{2}\right)>0$.

$(\partial k / \partial \gamma)=-\left(4 b(a-c) \theta\left(4 b^{2}\left(3 \gamma^{2}+6 \gamma \delta-4 \delta^{2}\right)+b \gamma\right.\right.$ $\left.(3 \gamma-8 \delta) \delta \theta^{2}-\gamma^{2} \delta^{2} \theta^{4}\right) / \quad\left(16 b^{2}(\gamma+\delta)+b \gamma(\gamma+8 \delta)\right.$ $\left.\left.\theta^{2}+\gamma^{2} \delta \theta^{4}\right)^{2}\right)$, therefore, when $\delta_{0}<\delta<\delta_{1}$, then $(\partial k / \partial \gamma)<0$; when $\delta_{1} \leq \delta$, then $(\partial k / \partial \gamma) \geq 0$, where $\delta_{0}=\left(3 b \gamma / 4 b+\lambda \theta^{2}\right), \quad \delta_{1}=\left(24 b^{2} \gamma+3 b \gamma^{2} \theta^{2}+\sqrt{3}\right.$ $\sqrt{448 b^{4} \gamma^{2}+176 b^{3} \gamma^{3} \theta^{2}+19 b^{2} \gamma^{4} \theta^{4}} / 2\left(16 b^{2}+8 b \gamma \theta^{2}+\right.$ $\left.\left.\gamma^{2} \theta^{4}\right)\right)$

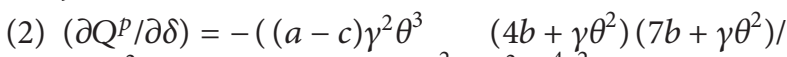
$\left.\left(16 b^{2}(\gamma+\delta)+b \gamma(\gamma+8 \delta) \theta^{2}+\gamma^{2} \delta \theta^{4}\right)^{2}\right)<0$.

$\left(\partial Q^{p} / \partial \gamma\right)=\left((a-c) \theta^{3}\left(4 b^{2}\left(3 \gamma^{2}+6 \gamma \delta-4 \delta^{2}\right)+b \gamma\right.\right.$ $\left.(3 \gamma-8 \delta) \delta \theta^{2}-\gamma^{2} \delta^{2} \quad \theta^{4}\right) /\left(16 b^{2}(\gamma+\delta)+b \gamma(\gamma+8 \delta)\right.$ $\left.\left.\theta^{2}+\gamma^{2} \delta \theta^{4}\right)^{2}\right)$, therefore, when $\delta_{0}<\delta<\delta_{1}$, then $\left(\partial Q^{P} / \partial \gamma\right)>0$; when $\delta_{1} \leq \delta$, then $\left(\partial Q^{P} / \partial \gamma\right) \leq 0$

(3) $\left(\partial M^{P} / \partial \delta\right)=\left(4 b(a-c) \gamma \theta \quad\left(28 b^{2}+11 b \gamma \theta^{2}+\gamma^{2} \theta^{4}\right) /\right.$ $\left.\left(16 b^{2}(\gamma+\delta)+b \gamma(\gamma+8 \delta) \theta^{2}+\gamma^{2} \delta \theta^{4}\right)^{2}\right)>0$.

$\left(\partial M^{P} / \partial \gamma\right)=-\left((a-c) \theta\left(112 b^{3} \delta+b^{2} \quad\left(-3 \gamma^{2}+8 \gamma \delta+\right.\right.\right.$ $\left.\left.16 \delta^{2}\right) \theta^{2}-2 b \gamma(\gamma-4 \delta) \delta \theta^{4}+\gamma^{2} \delta^{2} \theta^{6}\right) /\left(16 b^{2}(\gamma+\delta)+\right.$ $\left.\left.b \gamma(\gamma+8 \delta) \theta^{2}+\gamma^{2} \delta \theta^{4}\right)^{2}\right)<0$.

\section{Proof of Proposition 4}

(1) $\left(\partial \Pi_{C}^{P} / \partial \delta\right)=-\left(4 b(a-c)^{2} \gamma^{3}\left(4 b+\gamma \theta^{2}\right)\left(7 b \theta+\gamma \theta^{3}\right)^{2} /\right.$ $\left.\left(16 b^{2}(\gamma+\delta)+b \gamma(\gamma+8 \delta) \theta^{2}+\gamma^{2} \delta \theta^{4}\right)^{3}\right)<0$.

(2) $\partial \Pi_{C}^{P} / \partial \gamma=-\left(\left((a-c)^{2} \theta^{2} \quad\left(-16 b^{4}\left(33 \gamma^{3}+99 \gamma^{2} \delta-\right.\right.\right.\right.$ $\left.\left.48 \gamma \delta^{2}-16 \delta^{3}\right)\right)+b^{3} \gamma \quad\left(-87 \gamma^{3}-408 \gamma^{2} \delta+432 \gamma \delta^{2}+\right.$ $\left.256 \delta^{3}\right) \theta^{2}+3 b^{2} \gamma^{2} \delta \quad\left(-7 \gamma^{2}+24 \gamma \delta+32 \delta^{2}\right) \theta^{4}+b \gamma^{3} \delta^{2}$ $\left.\left.(3 \gamma+16 \delta) \theta^{6}+\gamma^{4} \delta^{3} \theta^{8}\right)\right) / \quad\left(2\left(16 b^{2}(\gamma+\delta)+b \gamma(\gamma+\right.\right.$

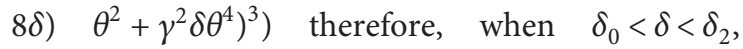
then $\left(\partial \Pi_{C}^{P} / \partial \gamma\right)>0$; when $\delta_{2} \leq \delta$, then $\left(\partial \Pi_{C}^{P} / \partial \gamma\right) \leq 0$, where $\delta_{2}=-\left(b \gamma\left(16 b+\gamma \theta^{2}\right) /\left(4 b+\gamma \theta^{2}\right)^{2}\right)$.

(3) $\left(\partial \Pi_{D}^{P} / \partial \delta\right)=-\left(2 b(a-c)^{2} \gamma^{2}(\gamma+\delta) \quad \theta^{2}\left(4 b+\gamma \theta^{2}\right)^{2}\right.$ $\left.\left(7 b+\gamma \theta^{2}\right) /\left(16 b^{2}(\gamma+\delta)+b \gamma(\gamma+8 \delta) \theta^{2}+\gamma^{2} \delta \theta^{4}\right)^{3}\right)<0$.

(4) $\left(\partial \Pi_{D}^{P} / \partial \gamma\right)=\left(2 b(a-c)^{2}(\gamma+\delta)\left(4 b+\gamma \theta^{2}\right)\left(4 b^{2}\left(3 \gamma^{2}+\right.\right.\right.$ $\left.\left.6 \gamma \delta-4 \delta^{2}\right) \theta^{2}+\quad b \gamma(3 \gamma-8 \delta) \delta \theta^{4}-\gamma^{2} \delta^{2} \theta^{6}\right) /\left(16 b^{2}\right.$ $\left.\left.(\gamma+\delta)+b \gamma(\gamma+8 \delta) \theta^{2}+\gamma^{2} \delta \theta^{4}\right)^{3}\right)$, therefore, when $\delta_{0}<\delta<\delta_{1}$, then $\left(\partial \Pi_{D}^{P} / \partial \gamma\right)>0$; when $\delta_{1} \leq \delta$, then $\left(\partial \Pi_{D}^{P} / \partial \gamma\right) \leq 0$, where $\delta_{1}=\left(24 b^{2} \gamma+3 b \gamma^{2} \theta^{2}+\right.$ $\sqrt{3} \sqrt{448 b^{4} \gamma^{2}+176 b^{3} \gamma^{3}} \quad \theta^{2}+19 b^{2} \gamma^{4} \theta^{4} / 2\left(16 b^{2}+\right.$ $\left.\left.8 b \gamma \theta^{2}+\gamma^{2} \theta^{4}\right)\right)$.

Proof of Proposition 5

(1) $\omega^{0}-\omega^{P}=\omega^{R}-\omega^{P}=-\left((a-c) \gamma \theta\left(4 b \delta-3 b \gamma+\gamma \delta \theta^{2}\right) / 2\right.$ $\left.\left(16 b^{2} \gamma+16 b^{2} \delta+b \gamma^{2} \theta^{2}+8 b \gamma \delta \theta^{2}+\quad \gamma^{2} \delta \theta^{4}\right)\right)<0$, that is $\omega^{0}=\omega^{R}<\omega^{P}$.

(2) $q^{0}-q^{P}=q^{R}-q^{P}=\left((a-c) \gamma \theta^{2}\left(-3 b \gamma+4 b \delta+\quad \gamma \delta \theta^{2}\right) /\right.$ $\left.4 b\left(16 b^{2}(\gamma+\delta)+b \gamma(\gamma+8 \delta) \quad \theta^{2}+\gamma^{2} \delta \theta^{4}\right)\right)>0(d>$ $(3 \beta \lambda /(4 \beta+\lambda)))$, that is $q^{0}=q^{R}>q^{P}$

Proof of Proposition 6

(1) $M^{R}-M^{P}=\left((a-c) \gamma \theta\left(12 b^{2}(\gamma+\delta)+b \delta(-3 \gamma+4 \delta)\right.\right.$ $\left.\theta^{2}+\gamma \delta^{2} \theta^{4}\right) / 4 b(\gamma+\delta)\left(16 b^{2}(\gamma+\delta)+b \gamma(\gamma+8 \delta) \quad \theta^{2}+\right.$ $\left.\left.\gamma^{2} \delta \theta^{4}\right)\right)>0$, that is $0=M^{0}<M^{P}<M^{R}$.

(2) $N^{0}-N^{R}=((a-c) \delta \theta / 4 b(\gamma+\delta))>0, \quad N^{0}-N^{P}=$ $\left((a-c) \theta\left(4 b+\gamma \theta^{2}\right)\left(-3 b \gamma+4 b \delta+\quad \gamma \delta \theta^{2}\right) / 4 b\left(16 b^{2}\right.\right.$ 
$\left.\left.(\gamma+\delta)+b \gamma(\gamma+8 \delta) \theta^{2}+\gamma^{2} \delta \theta^{4}\right)\right)>0, \quad N^{R}-N^{P}=$ $\left((a-c) \gamma \theta\left(-12 b^{2}(\gamma+\delta)+b \gamma(-\quad 3 \gamma+4 \delta) \theta^{2}+\gamma^{2} \delta\right.\right.$ $\left.\left.\theta^{4}\right) / 4 b(\gamma+\delta)\left(16 b^{2}(\gamma+\delta)+b \gamma(\gamma+8 \delta) \theta^{2}+\gamma^{2} \delta \theta^{4}\right)\right)$, therefore, when $\gamma>\left(2 b / \theta^{2}\right)$ and $\delta>\delta_{3}$, then $N^{P}<N^{R}<N^{0}$; otherwise $N^{R} \leq N^{P}<N^{0}$, where $\delta_{3}=$ $\left(3 \gamma\left(4 b^{2}+b \gamma \theta^{2}\right) / 4 b \gamma \theta^{2}+\gamma^{2} \theta^{4}-12 b^{2}\right)$.

\section{Proof of Proposition 7}

(1) $\Pi_{C}^{R}-\Pi_{C}^{0}=\left((a-c)^{2} \gamma \delta^{2} \theta^{2} / 32 b^{2}(\gamma+\delta)^{2}\right)>0$.

$\Pi_{C}^{0}-\quad \Pi_{C}^{P}=\left((a-c)^{2} \gamma \theta^{2}\left(b^{3}\left(-132 \gamma^{2}+128 \gamma \delta+\right.\right.\right.$ $\left.64 \delta^{2}\right)+b^{2} \gamma\left(-15 \gamma^{2}+40 \gamma \delta+48 \delta^{2}\right) \theta^{2}+2 b \gamma^{2} \delta \quad(\gamma+$

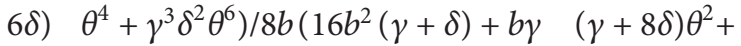
$\left.\left.\gamma^{2} \delta \theta^{4}\right)^{2}\right)>0$, that is $\Pi_{C}^{P}<\Pi_{C}^{N}<\Pi_{C}^{S}$.

(2) $\Pi_{D}^{N}-\Pi_{D}^{P}=\Pi_{D}^{S}-\Pi_{D}^{P}=\left((c-\alpha)^{2} 128 d^{2} \beta^{3} \lambda+80 d^{2} \beta^{2}\right.$ $\lambda^{2}+32 d \beta^{3} \lambda^{2}+16 d^{2} \beta \lambda^{3}+16 d \beta^{2} \lambda^{3}-96 \beta^{3} \lambda^{3}+d^{2}$ $\lambda^{4}+2 d \beta \lambda^{4}-15 \beta^{2} \lambda^{4} / 16 \beta\left(d(4 \beta+\lambda)^{2}+\beta \lambda(16 \beta+\right.$ $\left.\lambda))^{2}\right)>0$, that is $\Pi_{D}^{P}<\Pi_{D}^{0}=\Pi_{D}^{R}$.

\section{Data Availability}

The data used to support the findings of this study are included within the article.

\section{Conflicts of Interest}

The authors declare no conflicts of interest.

\section{Acknowledgments}

This work was supported by the Ministry of Education in China Project of Humanities and Social Sciences (no. 17YJA630078), Sichuan Province Cyclic Economy Research Center Project (no. XHJJ-1811), the Sichuan Science and Technology Department Soft Science Project (no. 2019JDR0148), Chengdu Science and Technology Bureau Project (no. 2017-RK00-00209-ZF), and Sichuan University (no. skqy201740).

\section{References}

[1] L. Zheng, H. Wu, H. Zhang et al., "Characterizing the generation and flows of construction and demolition waste in China," Construction and Building Materials, vol. 136, pp. 405-413, 2017.

[2] Q. Chen, Q. Zhang, C. Qi, A. Fourie, and C. Xiao, "Recycling phosphogypsum and construction demolition waste for cemented paste backfill and its environmental impact," Journal of Cleaner Production, vol. 186, pp. 418-429, 2018.

[3] J.-L. Gálvez-Martos, D. Styles, H. Schoenberger, and B. Zeschmar-Lahl, "Construction and demolition waste best management practice in Europe," Resources, Conservation and Recycling, vol. 136, pp. 166-178, 2018.

[4] M. U. Hossain, C. S. Poon, I. M. C. Lo, and J. C. P. Cheng, "Comparative environmental evaluation of aggregate production from recycled waste materials and virgin sources by LCA," Resources, Conservation and Recycling, vol. 109, pp. 67-77, 2016.
[5] I. Vegas, K. Broos, P. Nielsen, O. Lambertz, and A. Lisbona, "Upgrading the quality of mixed recycled aggregates from construction and demolition waste by using near-infrared sorting technology," Construction and Building Materials, vol. 75, pp. 121-128, 2015.

[6] BJX, "Annual development report of construction waste treatment industry," 2019, http://huanbao.bjx.com.cn/news/ 20190209/961476.shtml.

[7] Ministry of Hosing and Urban-Rural Development, Regulations for the Management of Urban Construction Waste, Ministry of Hosing and Urban-Rural Development, Beijing, China, 2005.

[8] The State Council of the People's Republic of China, Several Opinions on Further Strengthening the Management of Urban Planning and Construction, The State Council of the People's Republic of China, Beijing, China, 2016.

[9] Beijing Municipal Commission of Housing and Urban-Rural Development, Opinions on Further Strengthening the Utilization of Construction Waste, Beijing Municipal Commission of Housing and Urban-Rural Development, Beijing, China, 2018.

[10] Justice Bureau of Shenzhen Municipality, Measures for the Supervision and Management of Construction Waste, Justice Bureau of Shenzhen Municipality, Shenzhen, China, 2020.

[11] BJX, "The recycling rate of construction waste is less than 5\%," 2019, http://huanbao.bjx.com.cn/news/20190211/961664. shtml.

[12] H. Yuan and J. Wang, "A system dynamics model for determining the waste disposal charging fee in construction," European Journal of Operational Research, vol. 237, no. 3, pp. 988-996, 2014.

[13] S. Lockrey, H. Nguyen, E. Crossin, and K. Verghese, "Recycling the construction and demolition waste in Vietnam: opportunities and challenges in practice," Journal of Cleaner Production, vol. 133, pp. 757-766, 2016.

[14] L. Ma and L. Zhang, "Evolutionary game analysis of construction waste recycling management in China," Resources, Conservation and Recycling, vol. 161, Article ID 104863, 2020.

[15] J. Wang, H. Wu, V. W. Y. Tam, and J. Zuo, "Considering lifecycle environmental impacts and society's willingness for optimizing construction and demolition waste management fee: an empirical study of China," Journal of Cleaner Production, vol. 206, pp. 1004-1014, 2019.

[16] J. R. Li, G. H. He, and X. Z. Zhong, "Research on policy instruments selection of construction and demolition waste recycling management in Japan, Germany and Singapore," Construction Economy, vol. 5, pp. 87-90, 2017.

[17] People's Government of Guangdong Province, Guiding Opinions on Regulating the Price of Urban Construction Waste Disposal Management, People's Government of Guangdong Province, Guangzhou, China, 2013.

[18] J. Li, Y. Yao, J. Zuo, and J. Li, "Key policies to the development of construction and demolition waste recycling industry in China," Waste Management, vol. 108, pp. 137-143, 2020.

[19] L. Du, Y. Feng, W. Lu, L. Kong, and Z. Yang, "Evolutionary game analysis of stakeholders' decision-making behaviours in construction and demolition waste management," Environmental Impact Assessment Review, vol. 84, Article ID 106408, 2020.

[20] C. Knoeri, C. R. Binder, and H.-J. Althaus, "Decisions on recycling: construction stakeholders' decisions regarding recycled mineral construction materials," Resources, Conservation and Recycling, vol. 55, no. 11, pp. 1039-1050, 2011. 
[21] S. O. Ajayi and L. O. Oyedele, "Policy imperatives for diverting construction waste from landfill: experts' recommendations for UK policy expansion," Journal of Cleaner Production, vol. 147, pp. 57-65, 2017.

[22] B. Huang, X. Wang, H. Kua, Y. Geng, R. Bleischwitz, and J. Ren, "Construction and demolition waste management in China through the 3R principle," Resources, Conservation and Recycling, vol. 129, pp. 36-44, 2018.

[23] M. S. Aslam, B. Huang, and L. Cui, "Review of construction and demolition waste management in China and USA," Journal of Environmental Management, vol. 264, Article ID 110445, 2020.

[24] T. M. W. Mak, P.-C. Chen, L. Wang, D. C. W. Tsang, S. C. Hsu, and C. S. Poon, "A system dynamics approach to determine construction waste disposal charge in Hong Kong," Journal of Cleaner Production, vol. 241, Article ID 118309, 2019.

[25] S. Jia, G. Yan, A. Shen, and J. Zheng, "Dynamic simulation analysis of a construction and demolition waste management model under penalty and subsidy mechanisms," Journal of Cleaner Production, vol. 147, pp. 531-545, 2017.

[26] T. T. Liu, J. Zhang, and M. M. Hu, "Analysis on environmental benefits of construction and demolition waste recycling: a case study in Chongqing," China Environmental Science, vol. 38, no. 10, pp. 3853-3867, 2018.

[27] J. G. Chen and S. C. Yuan, "Simulating evaluation on the policies of construction and demolition waste sorting and recycling: analysis based on different subsidy amount," Urban Problems, vol. 7, pp. 27-34, 2017.

[28] J. K. Liu, Y. S. Wang, W. J. Zhang, and Z. T. Zheng, "Costbenefit analysis of construction and demolition waste management based on system dynamics: a case study of Guangzhou," Systems Engineering-Theory \& Practice, vol. 34, no. 6, pp. 1480-1490, 2014.

[29] M. Wang, Y. M. Li, W. Q. Shi, L. Hao, and S. P. Quan, "The dynamic analysis and simulation of different government regulations in product-recovery supply chain," Systems Engineering-Theory \& Practice, vol. 40, no. 1, pp. 103-118, 2020.

[30] J.-B. Sheu and X.-Q. Gao, "Alliance or no alliance-Bargaining power in competing reverse supply chains," European Journal of Operational Research, vol. 233, no. 2, pp. 313-325, 2014.

[31] L. Lu, X. Qi, and Z. Liu, "On the cooperation of recycling operations," European Journal of Operational Research, vol. 233, no. 2, pp. 349-358, 2014.

[32] R. A. Begum, C. Siwar, J. J. Pereira, and A. H. Jaafar, "Attitude and behavioral factors in waste management in the construction industry of Malaysia," Resources, Conservation and Recycling, vol. 53, no. 6, pp. 321-328, 2009.

[33] Z. Wu, A. T. W. Yu, and L. Shen, "Investigating the determinants of contractor's construction and demolition waste management behavior in Mainland China," Waste Management, vol. 60, pp. 290-300, 2017.

[34] Y. Liu and Y. Bai, “An exploration of firms' awareness and behavior of developing circular economy: an empirical research in China," Resources, Conservation and Recycling, vol. 87, pp. 145-152, 2014.

[35] H. Yuan and L. Shen, "Trend of the research on construction and demolition waste management," Waste Management, vol. 31, no. 4, pp. 670-679, 2011.

[36] J. Chen, C. Hua, and C. Liu, "Considerations for better construction and demolition waste management: identifying the decision behaviors of contractors and government departments through a game theory decision-making model," Journal of Cleaner Production, vol. 212, pp. 190-199, 2019.
[37] K. Joseph, "Stakeholder participation for sustainable waste management," Habitat International, vol. 30, no. 4, pp. 863-871, 2006.

[38] J. Liu, J. Nie, and H. Yuan, "Interactive decisions of the waste producer and the recycler in construction waste recycling," Journal of Cleaner Production, vol. 256, Article ID 120403, 2020.

[39] China Construction Industry Association, "Statistical analysis of construction industry development in 2020," 2021, http:// www.zgjzy.org.cn/newsList/46/1.html.

[40] S. Alizamir, F. Iravani, and H. Mamani, "An analysis of price vs. revenue protection: government subsidies in the agriculture industry," Management Science, vol. 65, no. 1, pp. 32-49, 2019.

[41] T.-H. Tsai, C.-C. Wang, and J.-R. Chiou, "Can privatization be a catalyst for environmental R\&D and result in a cleaner environment?" Resource and Energy Economics, vol. 43, pp. 1-13, 2016.

[42] Q. Wang, D. Zhao, and L. He, "Contracting emission reduction for supply chains considering market low-carbon preference," Journal of Cleaner Production, vol. 120, pp. 7284, 2016.

[43] Y. Ouchida and D. Goto, "Do emission subsidies reduce emission? In the context of environmental R\&D organization," Economic Modelling, vol. 36, pp. 511-516, 2014.

[44] J. A. Poyago-Theotoky, "The organization of R\&D and environmental policy," Journal of Economic Behavior \& Organization, vol. 62, no. 1, pp. 63-75, 2007.

[45] M. David and B. Sinclair-Desgagné, "Pollution abatement subsidies and the eco-industry," Environmental and Resource Economics, vol. 45, no. 2, pp. 271-282, 2010.

[46] R. Pal and B. Saha, "Pollution tax, partial privatization and environment," Resource and Energy Economics, vol. 40, pp. 19-35, 2015.

[47] A. Arya and B. Mittendorf, "Supply chain consequences of subsidies for corporate social responsibility," Production and Operations Management, vol. 24, no. 8, pp. 1346-1357, 2015.

[48] J. Liu, Y. Yi, and X. Wang, "Exploring factors influencing construction waste reduction: a structural equation modeling approach," Journal of Cleaner Production, vol. 276, Article ID 123185, 2020.

[49] F. Yuan, L.-Y. Shen, and Q.-M. Li, "Emergy analysis of the recycling options for construction and demolition waste," Waste Management, vol. 31, no. 12, pp. 2503-2511, 2011.

[50] L. L. He and H. P. Yuan, "Investigation of construction waste recycling decisions by considering consumers' quality perceptions," Journal of Cleaner Production, vol. 259, 2020.

[51] H. Li, X. Zhang, S. T. Ng, and M. Skitmore, "Quantifying stakeholder influence in decision/evaluations relating to sustainable construction in China-a Delphi approach," Journal of Cleaner Production, vol. 173, pp. 160-170, 2018.

[52] J. Wang, H. Yuan, X. Kang, and W. Lu, "Critical success factors for on-site sorting of construction waste: a China study," Resources, Conservation and Recycling, vol. 54, no. 11, pp. 931-936, 2010. 